\title{
Prevention of boar taint in pig production. Factors affecting the level of skatole Bent Borg Jensen*
}

Address: Department of animal health, welfare and nutrition, Danish Institute of Agricultural Sciences, Tjele, Denmark

* Corresponding author

from Prevention of Boar Taint in Pig Production: The 19th Symposium of the Nordic Committee for Veterinary Scientific Cooperation Gardermoen, Norway. 2I-22 November 2005

Published: 7 August 2006

Acta Veterinaria Scandinavica 2006, 48(Suppl I):S6 doi:I0.II86/I75I-0I47-48-SI-S6

(C) 2006 Jensen.; licensee BioMed Central Ltd.

\section{Introduction}

The indolic compound skatole is produced by microbial degradation of the amino acid tryptophan and has been detected in the rumen of cows and the caecum and colon of pigs. Together with the testicular steroid androstenone skatole is considered to be the main contributor to boar taint.

Several studies in our laboratory have shown that microbial degradation of tryptophan by pig gastrointestinal bacteria results mainly in the two volatile indolic compounds indole and skatole, skatole via a transient accumulation of indole acetic acid (IAA). Analogously with indole and skatole, indole propionic acid is also an end product of tryptophan metabolism, and has recently been shown to be produced in small amounts in the hind gut of pigs [1]. While the conversion of tryptophane to indole and IAA is performed by a variety of bacteria, only very few bacteria species are capable of further degradation of IAA to skatole [2]. The production of skatole increases through the colon and reaches a maximum in the distal part of the large intestine. From the intestinal tract, a portion of the produced skatole is absorbed to the blood and transported via the portal vein to the liver, where more than half of the amount absorbed is degraded by cytochrome P450. It has been demonstrated that the liver extraction is relatively constant within the individual animal, but varies between animals, and between sexes, showing a lower elimination rate of skatole in male pigs than female pigs [3]. Skatole avoiding degradation in the liver is deposited in peripheral tissues and due to the lipophilic characteristics of skatole the majority accumulates in the adipose tissue. To summarize, the amount of skatole stored in adipose tissue depends on the concentration in the peripheral blood, which is influenced by the production in the large intestine and the degradation capacity of the liver. As the production of skatole is the incipient cause of tainted meat a limitation of the microbial fermentation of tryptophan in the large intestine would be an effective approach to solve the problem with boar odour caused by skatole.

\section{Factors affecting the level of skatole Diet composition}

One essential tool for manipulating the microbial activity and such the production of skatole in the gastro-intestinal tract is diet composition [4]. Several studies have provided evidence that the amount and type of protein and carbohydrate present in the feed has a substantial effect on nitrogen metabolism, thereby influencing the formation of skatole $[5,6]$. In accordance with this, it has been shown that diets containing a protein source with low precaecal digestibility stimulate skatole production $[7,8]$ whereas diets with high content of fermentable carbohydrates that escape digestion in the small intestine have been shown to reduce the production of skatole, however, the results vary. Øverland et al., [9] and Van Oeckel et al., [10] found no effect of diets rich in sugar beat pulp, whereas Jensen et al. [8], Kjeldsen [11], Knarreborg et al. [1] and Whittington [12] observed significant reduction in skatole levels in pigs fed sugar beet pulp. Fructooligosaccharides has also been shown to reduce skatole production in both in vitro [13] and in vivo models [14,2]. Raw potato starch has also been shown to reduce the production of skatole $[2,15,16]$. In the study of Jensen and Jensen, [2] seven different fibre sources were investigated 


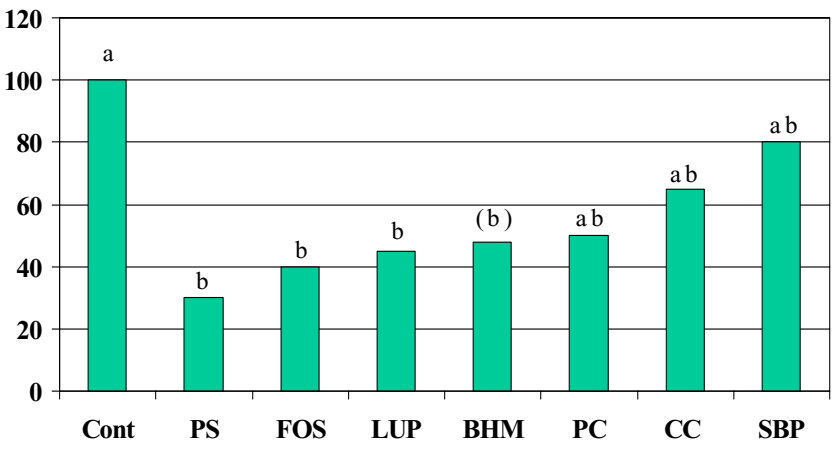

Figure I

Effect of various dietary fibre sources on the concentration of skatole in blood plasma. The diets were: a control diet based on barley and soya bean (Cont), seven diets with the same basal composition as the control, but with addition of $100 \mathrm{~g} \mathrm{~kg}^{-1}$ of either raw potato starch (PS), fructooligosaccharides (FOS), lupins (LUP), barley hull meal (BHM), palm cake (PC), coconut cake (CC) or sugar beat pulp (SBP). All blood samples were taken 3 hours after the morning feeding. The control diet for each individual animal was given the value 100 and the other diets were related to this. The value for each fibre source represent three to four replicates with different animals.

for their effect to reduce skatole production. Raw potato starch, fructooligosaccharides and lupins were found to be most effective (Figure 1).

The exact mechanism of how fibre-rich diets affect skatole deposition in back fat is not known, but several contradic- tory hypotheses have been presented. Firstly, in the presence of extra dietary fibre, more undigested protein will reach the large intestine with consequently more degradation of tryptophan to skatole. Secondly, more fermentable carbohydrates in the hindgut will increase the microbial activity in the gastrointestinal tract [17] resulting in more tryptophan incorporated as bacterial protein, further increased amounts of carbohydrates will decrease the activity of the proteolytic bacteria resulting in less tryptophan available for skatole production. Thirdly, extra dietary fibre results in more bulky material in the large intestine and an increased water binding capacity, leading to a dilution of skatole resulting in less contact of skatole with the intestinal wall and consequently, decreased skatole absorption [2]. Further, dietary fibre decreases the intestinal transit time and as such may decrease skatole absorption from the gut. Recently it has been hypotized that carbohydrates with high pre-ceacal digestibility will increase cell debris formation in the small intestine, resulting in more tryptophan entering the large intestine and as such higher skatole formation [18]. On the other hand carbohydrates with low pre-caecal digestibility will decrease skatole production due to an increased butyrate production that inhibits apoptosis and as such less tryptophan available for skatole production.

That the production of skatole in the hindgut is dependent on the composition of the diet is illustrated by a series of experiments [19] where the production of skatole in the hindgut and the absorption of skatole to the portal blood was investigated after tryptophan was infused into the caecum of pigs fed either a low or a high fibre diet. Figure 2 shows the absorption pattern of skatole over a period

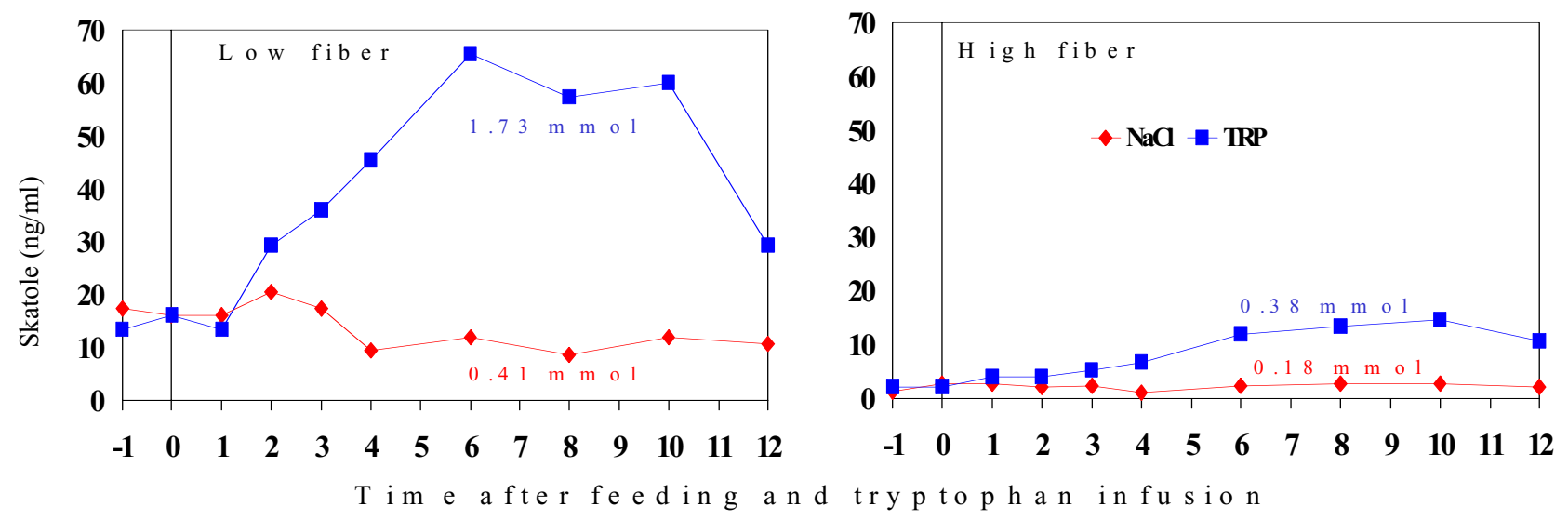

Figure 2

Effect of dietary fibre on absorption patterns ( $\mathrm{V} p$ - $\mathrm{Vj}$ differences) of skatole to the portal blood following tryptophane (4,9 $\mathrm{mmol}$ ) or saline infusion in the caecum. The area under curves (AUC) represent the total amount of skatole absorbed. Both diets were similar except that the high fibre diet was added $100 \mathrm{~g}$ sugar beet pulp per $\mathrm{kg}$. 
Table I: Influence of dietary fibre on microbial degradation of tryptophan (TRP) to indole, indole propionic acid (IPA) and skatole in the hind gut of male pigs.

\begin{tabular}{|c|c|c|c|c|c|c|c|c|}
\hline \multirow[b]{2}{*}{ Fibre content } & \multicolumn{2}{|c|}{ Indole*) } & \multicolumn{2}{|c|}{ IPA*) } & \multicolumn{2}{|c|}{ Skatole*) } & \multicolumn{2}{|c|}{ Total indoles*) } \\
\hline & Low & High & Low & High & Low & High & Low & High \\
\hline Basic production in the hind gut, $12 \mathrm{~h}$ & 960 & 290 & 10 & 30 & 480 & 230 & 1450 & 550 \\
\hline Total production following infusion of TRP, $12 \mathrm{~h}$ & 4360 & 2000 & 370 & 800 & 1760 & 540 & 6490 & 3340 \\
\hline Production caused by infusion of TRP & 3400 & 1710 & 360 & 770 & 1280 & 310 & 5040 & 2790 \\
\hline Infused TRP & 4900 & 4900 & 4900 & 4900 & 4900 & 4900 & 4900 & 4900 \\
\hline Percent of infused TRP converted & $69 \%$ & $35 \%$ & $7 \%$ & $16 \%$ & $26 \%$ & $6 \%$ & $103 \%$ & $57 \%$ \\
\hline
\end{tabular}

*) Values in $\mu \mathrm{mol}$

from 1 hour before to 12 hours after infusion of either tryptophan or saline.

Both the effect of available tryptophan and the effect of fibre on skatole are convincing. With the low fibre diet, the hindgut bacteria transform $26 \%$ of the infused tryptophan into skatole (Table 1) resulting in significant increase in skatole concentration in the portal blood (Figure 2).

Approximately $70 \%$ of the produced skatole was recovered in the portal blood. On the high fibre diet, however, only $6 \%$ of the infused tryptophan was converted to skatole in the gastrointestinal tract, resulting in a lower increase in portal blood skatole concentration. Again approximately $70 \%$ of the skatole produced in the hindgut was absorbed to the portal blood. Also the basal skatole production in the hindgut and absorption to the portal blood were affected by the fibre content in the diet. With the high fibre diet only $230 \mu \mathrm{mol}$ skatole was produced during the 12 hours, while more than twice as much $(480 \mu \mathrm{mol})$ was produced on the low fibre diet. These results strongly show the usefulness of in vitro measurements of skatole production and the use of portal absorption to study the effect of diet on the production and absorption of microbial metabolites in the large intestine, and confirm the important effect of diet composition on the amount of skatole produced and absorbed from the gut. Further, the results point at the use of fibre rich diets as a relevant way to reduce boar taint due to skatole in practical pig production.

\section{Feeding strategies}

Two feeding strategies that have a marked effect on the gastrointestinal ecosystem are liquid feeding [20] and the structure of the feed (pellets vs. meal/fine vs. gorse) [21]. While use of liquid feed has been shown to reduce the level of skatole [22], it has never been investigated if the feed structure has any effect on skatole levels.

\section{Feed intake (fasting)}

Studies with different feeding levels during the growth period of the pigs showed that the general feed intake had no effect on the skatole level, whereas a 12 hours redraw of feed from the pigs prior to slaughter did reduce the skatole level [11]. This is in agreement with that reduced amount of digesta entering the large intestine results in a lower fermentation of non-digested protein and the very rapid degradation of skatole in the liver. However, Anderson et al. [22], were unable to confirm that a 12 hours redraw of feed reduced skatole.

\section{Environmental factors}

Skatole levels depends on environmental conditions [23], and it has been shown that pigs raised in a clean environment have a lower skatole level than those raised in dirty environments [24].

\section{Puberty (age)}

Androstenone and other testicular steroids might be involved in the skatole level by regulation of skatole metabolism in the liver [16]. Androstenone is a pheromonal steroid produced in the testes of mature male pigs together with other steroids and its levels are primarily affected by puberty stage. Using in vitro experiments Doran et al. [25] have shown that androstenone suppress the induction of enzymes involved in skatole metabolism. Zamaratskaia et al. [16] found a positive correlation between the testicular hormones testosterone and oestrone sulphate and skatole level suggesting that these compounds have an influence on skatole pattern, and the authors suggest that slaughter of entire male pigs at a weight below $100 \mathrm{~kg}$ can be used to avoid boar taint.

\section{Genetics}

There are strong indications of genetic influences on skatole levels in pigs. These include differences in skatole levels between breeds [26], significant heritability estimates for levels of skatole in fat [27] as well as indications of the presence of a major gene affecting boar taint due to skatole [28]. 


\section{References}

I. Knarreborg A, Beck J, Jensen MT, Laue A, Agergaard N, Jensen BB Effect of non-starch polysaccharides on production and absorption of indolic compounds in entire male pigs. Animal Science 2002, 74:445-453.

2. Jensen BB, Jensen MT: Microbial production of skatole in the digestive tract of entire pigs. In Skatole and boar taint Edited by: Jensen WK. Roskilde. Denmark: Danish Meat Research Institute; 1998:293-304.

3. Friis C: Distribution, metabolic fate and elimination of skatole in the pig. Measurement and prevention of boar taint in entire male pigs. Roskilde Denmark. INRA, Paris (Les Collogues no. 60); 1993:II3-II5. 12-14 October 1992

4. Jensen BB: Impact of feed composition and feed processing on the gastrointestinal ecosystem in pigs. In Nutrition and gastrointestinal physiology - today and tomorrow (red. AJM Jansman and I Huisman) TNO Nutrition and Food Research Institute, Wageningen, The Netherlands; 1999:43-56.

5. Boyd WL, Lichstein HC: The effect of carbohydrates on the tryptophanase activity of bacteria. Journal of Bacteriology 1995, 69:584-589.

6. Misir R, Sauer WC: Effect of starch infusion at the terminal ileum on nitrogen balance and apparent digestibilities of nitrogen and amino acids in pigs fed meat-and-bone and soybean diets. Journal of Animal Science 1982, 64:448-456.

7. Jensen BB: [Skatole (boar taint). Microbial production of skatole in the gastro-intestinal tract of pigs]. Communication 772 Danish Institut of Agricultural Science, Tjele, Denmark; 1990.

8. Jensen MT, Cox RP, Jensen BB: Microbial production of skatole in the hindgut of pigs given different diets and its relation to skatole deposition in backfat. Animal Science 1995, 6 1:293-304.

9. Øverland M, Berg J, Matre T: The effect of feed and feeding regime on skatole and androstenone levels and on sensory attributes of entire male and female pigs. In Proceeding of the EAAP Working Group, Production and Utilisation of Meat from Entire Male Pigs Milton Keynes, UK; 1995.

10. Van Oeckel MJ, Warnants N, De Paepe M, Casteels M, Bouequé Ch.V: Effect of fibre-rich diets on the backfat skatole content of entire male pigs. Livestock Production Science 1998, 56:173-180.

I I. Kjeldsen N: Practical experience from field studies with entire male pigs. In Skatole and boar taint Edited by: Jensen WK. Roskilde. Denmark: Danish Meat Research Institute; 1998:129-136.

12. Whittingthon FM, Nute GR, Huges SI, McGivan JD, Lean LJ, Wood JD, Doran E: Relationships between skatole and androstenone accumulation and cytochrome P450EI expression in Meishan $\times$ Large White pigs. Meat Science 2004, 67:569-576.

13. $\mathrm{Xu} \mathrm{ZR,} \mathrm{Hu} \mathrm{CH,} \mathrm{Wang} \mathrm{MQ:} \mathrm{Effects} \mathrm{of} \mathrm{frugtooligosaccharides} \mathrm{on}$ conversion of L-tryptophan to skatole and indole by mixed populations of pig fecal bacteria. Journal of General Applied Microbiology 2002, 48:83-90.

14. Russell TJ, Kerley MS, Allee GJ, Howard MD: Fructooligosaccharides improves nitrogen metabolism and reduce fecal excretion of odour metabolites in the weaned pig. UMC Animal Science Department Rep 1998:79-83.

15. Lösel D, Claus R: Dose-dependent effects of resistant potato starch in the diet on intestinal skatole formation and adipose tissue accumulation in the pig. Journal of Veterinary Medicine 2005, 52:209-2। 2

16. Zamaratskaia G, Babol J, Anderson HK, Andersson K, Lundström K: Effect of live weight and dietary supplement of raw potato starch on the levels of skatole, Androstenone, testosterone and oestrone sulphate in entire male pigs. Livestock Production Science 2005, 93:235-243.

17. Jensen BB, Jørgensen BB: Effect of dietary fibre on microbial activity and microbial gas production in various regions of the gastrointestinal tract of pigs. Applied and Environmental Microbiology 1994, 60:1897-1904.

18. Claus RD, Lösel M, Lacorn M, Mentschel J, Schenkel H: Effects of butyrate on apoptosis in the pig colon and its consequences for skatole formation and tissue accumulation. Journal of Animal Science 1996, 81:239-248.

19. Agergaard N, Jensen BB, Laue A, Jensen MT: Production and absorption of skatole to the portal vein blood following tryptophan infusion to the hind gut. In Skatole and boar taint Edited by: Jensen WK. Roskilde. Denmark: Danish Meat Research Institute; 1997:97-110.
20. Jensen BB, Mikkelsen LL: Feeding liquid diets to pigs. In Recent advances in Animal Nutrition Edited by: Garnsworthy PC, Cole DJA. Nottingham University Press; 1998: 105-124.

21. Mikkelsen LL, Naughton PJ, Hedemann MS, Jensen BB: Effects of physical properties of feed on microbial ecology and survival of Salmonella enterica Serovar Typhimurium in the pig gastrointestinal tract. Appl Environ Microbiol 2004, 70:3485-3492.

22. Anderson K, Schaub A, Anderson K, Lundström K, Thomke S, Hansson I: The effect of feeding systems, lysine level and gilt contact on performance, skatole levels and economy of entire male pigs. Livestock Production Science 1997, 5 I:131-140.

23. Walstra $P$, Claudi-Magnussen $C$, Chevillon $P$, von Seth $G$, Diestre $A$ Matthews KR, Homer DB, Bonneau M: An international study on the importance of androstenone and skatole for boar taint: levels of androstenone and skatole by country and season. Livestock Production Science 1999, 62:15-28.

24. Hansen LL, Larsen AE, Jensen BB, Hansen-Møller J, Barton-Gade P. Influence of stocking rate and faeces deposition in the pen at different temperatures on skatole concentration (boar taint) in subcutaneous fat. Animal Production 1994, 59:99-I I0.

25. Doran E, Whittington FW, Wood JD, McGivan JD: Cytochrome P450IIEI (CYP2EI) is inducedby skatole and this induction is blocked by Androstenone in isolated pig hepatocytes. Chemico-Biological Interactions 2002, 104:81-82.

26. Babol J, Zamaratskaia G, Juneja RK, Lundström K: The effect of age on distribution of skatole and indole levels in entire male pigs in four breeds: Yokshire, Landrace, Hampshire and Duroc. Meat Science 2004, 67:351-358.

27. Pedersen B: Heritability of skatole in back fat. In Skatole and boar taint Edited by: Jensen WK. Roskilde. Denmark: Danish Meat Research Institute; 1998: I29-136.

28. Lundström K, Malmfors B, Stern S, Rydhymer L, Eliasson-Selling L, Mortensen AB, Mortensen HP: Skatole levels in pigs selected for high lean tissue growth rate on different protein levels. Livestock Production Science 1994, 38: I25-132.
Publish with Biomed Central and every scientist can read your work free of charge

"BioMed Central will be the most significant development for disseminating the results of biomedical research in our lifetime. "

Sir Paul Nurse, Cancer Research UK

Your research papers will be:

- available free of charge to the entire biomedical community

- peer reviewed and published immediately upon acceptance

- cited in PubMed and archived on PubMed Central

- yours - you keep the copyright
BioMedcentral 